\title{
Extending the Queue Question to Customer Purchase Rate to Predict the Probability of Customer Inactive
}

\author{
Hui-Hsin Huang \\ Department of Business Administration, Aletheia University, New Taipei City, Taiwan \\ Email address: \\ hoyasophia@gmail.com
}

\section{To cite this article:}

Hui-Hsin Huang. Extending the Queue Question to Customer Purchase Rate to Predict the Probability of Customer Inactive. American Journal of Data Mining and Knowledge Discovery. Vol. 4, No. 1, 2019, pp. 53-56. doi: 10.11648/j.ajdmkd.20190401.18

Received: April 17, 2019; Accepted: May 31, 2019; Published: June 24, 2019

\begin{abstract}
In the rapidly changing market, there is a never-ending sequence of marketing actions and competitive reactions. Customer may consume much volume to stockpile more than they need when the price promotion or some benefit that retail gives. Thus this paper explores the customer purchase rate, the speed of product consumption and the inactive probability with extending queue model. A real data set from the customer purchase behavior in two electronic business retailers website includes purchase volume, the duration of customer consumption (which is the interpurchase time between purchase behavior with the same product in the same brand) and the duration of variety-seeking (which is defined as customer purchase the same categories but different brand of product) to estimate the parameters and calculate the expectation value of product consumption and product stockpile volume. This result can make application for other industries such as e-commerce.
\end{abstract}

Keywords: Queue, Purchase Rate, The Speed of Product Consumption, Inactive Probability

\section{Introduction}

The knowledge of a customer's shopping behavior such as its purchasing pattern and response to a change in marketing variables is essential for retailers to succeed in today's market which is highly competitive and consumer-oriented $[1,2]$. The customer purchase rate, the speed of product consumption and the inactive probability are all valuable information for retailers to determine their marketing targets and strategies [3, 4]. Retailers who are not able to uncover the various needs of customers and then facilitate the fulfillment of those needs are doomed to failure $[5,6,7]$.

In the rapidly changing market, there is a never-ending sequence of marketing actions and competitive reactions that eventually shape both the structure of a market and the performance of its participants [8]. New product launched, distribution is developed, advertising campaigns are initiated, price adjusted and so on $[4,8]$. Customer may consume much volume to stockpile more than they need when the price promotion or some benefit that retail gives.

Thus, to analyze the purchase rate, consumption rate and inactive probability is a key element in customer valuation and can provide guidance for decisions such as resource allocation [9]. This paper uses queue concept model to construct customer purchase model.

This paper is organized as following: first, the queue model is demonstrated and the extended model with servicer vacation is introduced in part. Secondly, the customer purchase rate, consumption rate and inactive probability are applied from extended queue model. Thirdly, the parameters are estimated and expectation value of product consumption and product stockpile volume are also calculated in this section. Finally, the conclusion is made.

\section{The Model}

\subsection{The Queue Model}

This paper extends the queue model to meet the need of predicting customers' product use pattern. According to $\mathrm{M} / \mathrm{M} / 1$ queue, we consider customers' purchase rate which demonstrates customer is $1 / \lambda$ and the volume is a random variable $v$ which follows Possion distribution with parameter $\lambda$. The service rate in queue is considered as product consumption rate (duration) of customer in this paper. Thus, the product consumption rate which is considered as a random variable $c$ is following exponential distribution with parameter $\theta$. It is denoted that the probability density function is $f(c)$ and 
cumulative distribution function is $F(c)$.

Then, it can use hazard function to explore the customer completion of consumption product.

$$
h(c)=\frac{f(c)}{1-F(c)}=\theta
$$

\subsection{The Model Extension}

Based on Kalyanaraman and Suvitha [10], they supposed that as soon as the service of a customer is completed the server may go for a vacation. In this paper, we consider customer variety-seeking as similar pattern as server's vacation pattern. Customers' variety-seeking behavior is a consumer's desire to search for alternative products even if she or he is satisfied with a current product [11]. Variety-seeking is rooted in need for a change in an attempt to resolve the boredom associated with a brand and a product. Thus, the tendency of variety-seeking is a person who expresses the desire to try new and different things $[12,13]$. Consumers typically seek variety among hedonic products such as restaurant, hair salon or leisure activities [14].

The pattern of switching among brands can be induced by manipulation of marketing variables by the desire for variety $[16,15]$. After the inventory of product is running out, customers may purchase other brands (consider as variety-seeking behavior). In this situation, the pattern of purchase rate and consumption rate of origin brand will be influenced in next purchase behavior. It can be portrayed as server's vacation.

We consider the duration of customer variety-seeking to other brand is an exponential process with the parameter $\varphi$.

The expectation of product consumption rate can be calculated as

$$
\boldsymbol{E}(\boldsymbol{c})=\frac{\lambda\left(\phi^{2}+\theta^{2}+\phi \theta\right)}{\phi \theta[\phi \theta-\lambda(\phi+\theta)]}
$$

The expectation value of stockpile volume (v) is

$$
\boldsymbol{E}(\boldsymbol{v})=\frac{\lambda^{2}\left(\phi^{2}+\theta^{2}+\phi \theta\right)}{\phi \theta[\phi \theta-\lambda(\phi+\theta)]}
$$

When customer still uses his stock product, the expectation value of stockpile volume is

$$
E_{s t}(v)=\frac{\lambda^{2}\left(\phi^{2}+\phi \theta\right)}{\phi \theta[\phi \theta-\lambda(\phi+\theta)]}
$$

When customer becomes variety-seeking, the expectation value of stockpile volume is

$$
\boldsymbol{E}_{\boldsymbol{v} \boldsymbol{s}}(\boldsymbol{v})=\frac{\lambda^{2}(\phi-\lambda+\theta)}{\phi[\phi \theta-\lambda(\phi+\theta)]}
$$

Then we can calculate the probability of customer inactive which means stockpile volume is zero.

The probability that customer is out of stockpile volume is

$$
\boldsymbol{P}=\frac{\phi \theta-\lambda(\phi+\theta)}{\phi \theta}
$$

$\mathrm{P}$ can be considered as the expectation duration of the customer is out of stockpile volume and never purchase again.

\section{The Data Analysis}

We compare two service retailers, A and B in Taiwan. Both of them are electronic business company and selling synthesis product such as clothes, foods, life groceries and so on. The data from the customer purchase behavior in their website includes purchase volume, the duration of customer consumption (which is the interpurchase time between purchase behavior with the same product in the same brand) and the duration of variety-seeking (which is defined as customer purchase the same categories but different brand of product) (see figure 1).

We select and focus on three product categories, clothes, shoes and toilet paper to There are 43850 of retailer A and 58972 transactions of retailer B during 1 January to 31 March in 2018.
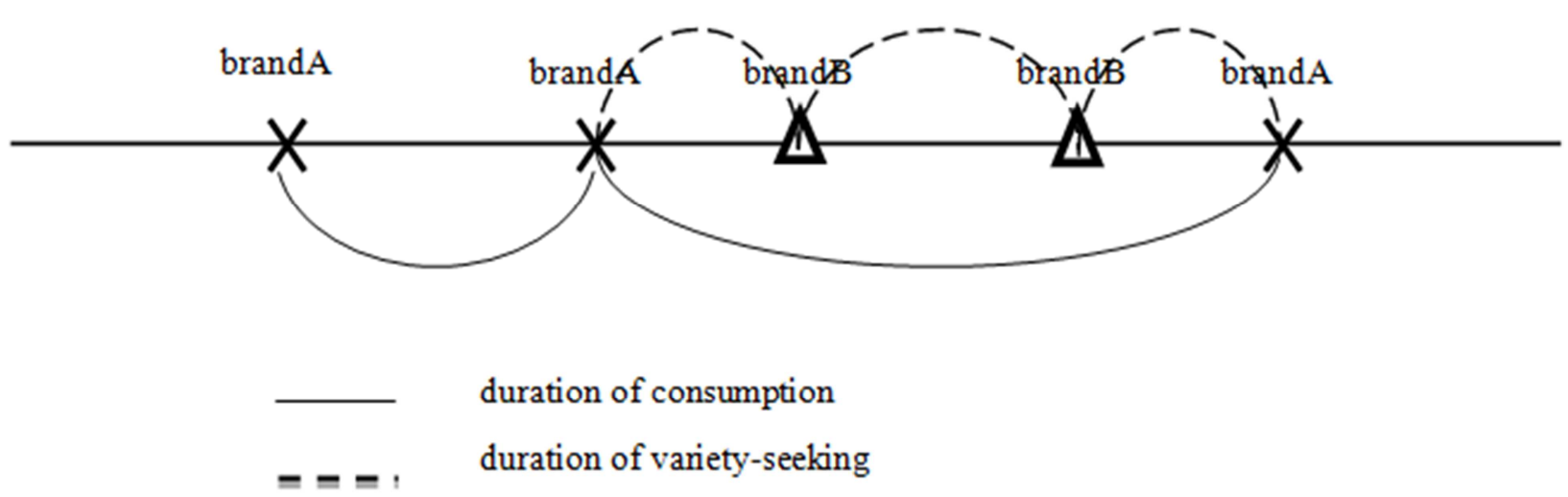

Figure 1. The duration of customer consumption 


\section{The Results of Analysis}

Table 1. The results of parameters estimation

\begin{tabular}{lllllll}
\hline category & Shoes $_{\text {A }}$ & Shoes $_{\text {B }}$ & Clothes $_{\text {A }}$ & Clothes $_{\text {B }}$ & $\begin{array}{l}\text { Toilet } \\
\text { Paper }_{\text {A }}\end{array}$ & $\begin{array}{l}\text { Toilet } \\
\text { Paper }_{\text {B }}\end{array}$ \\
\hline$\lambda$ & 1.75 & 1.28 & 4.52 & 3.33 & 7.54 & 5.28 \\
$\theta$ & 28.56 & 33.45 & 54.23 & 43.25 & 20.11 & 22.52 \\
$\varphi$ & 55.28 & 67.56 & 31.68 & 26.54 & 36.97 & 22.42 \\
\hline
\end{tabular}

probability of that customer is out of stockpile volume (P) is 0 . Then we can calculate the parameters $\lambda, \theta$ and $\varphi$. The results are shown in table 1.

The expectation value of $c$ and $v$ can be calculated by equation (1) to (5). The results are shown in table 2 . The mean of $c$ and $v$ in the real data are also shown in table 2 to compare the difference between estimation results and real data.

We assume that if the customer is inactive than the

Table 2. The expectation value of estimation

\begin{tabular}{lllllll}
\hline category & Shoes $_{\mathbf{A}}$ & Shoes $_{\mathbf{B}}$ & Clothes $_{\mathbf{A}}$ & Clothes $_{\mathbf{B}}$ & Toilet Paper $_{\mathbf{A}}$ & Toilet Paper $_{\mathbf{B}}$ \\
\hline $\mathrm{E}(\mathrm{c})$ & $0.42 * 10-2$ & $0.21 * 10-2$ & $1.121 * 10-2$ & $1.18 * 10-2$ & $0.815 * 10-2$ & $0.591 * 10-2$ \\
M(c) & $0.58 * 10-2$ & $0.18 * 10-2$ & $2.002 * 10-2$ & $1.12 * 10-2$ & $0.808 * 10-2$ & $10580 * 10-2$ \\
E(v) & $0.73 * 10-2$ & $0.27 * 10-2$ & $5.064 * 10-2$ & $3.92 * 10-2$ & $61.41 * 10-2$ & $31.25 * 10-2$ \\
M(v) & $0.68 * 10-2$ & $0.31 * 10-2$ & $5.069 * 10-2$ & $3.89 * 10-2$ & $60.45 * 10-2$ & $32.09 * 10-2$ \\
Est(v) & $0.62 * 10-2$ & $0.23 * 10-2$ & $2.434 * 10-2$ & $1.95 * 10-2$ & $51.54 * 10-2$ & $20.78 * 10-2$ \\
Mst(v) & $0.71 * 10-2$ & $0.28 * 10-2$ & $2.334 * 10-2$ & $1.98 * 10-2$ & $52.01 * 10-2$ & $21.01 * 10-2$ \\
Evs (v) & $0.31 * 10-2$ & $0.11 * 10-2$ & $3.9 * 10-2$ & $3.03 * 10-2$ & $24.33 * 10-2$ & $18.42 * 10-2$ \\
Mvs (v) & $0.33 * 10-2$ & $0.12 * 10-2$ & $3.5 * 10-2$ & $3.09 * 10-2$ & $24.58 * 10-2$ & $18.55 * 10-2$ \\
h(c) & 28.56 & 33.45 & 54.23 & 43.25 & 20.11 & 22.52 \\
\hline
\end{tabular}

$+\mathrm{M}(\mathrm{c})$ is the mean of product consumption. $\mathrm{M}(\mathrm{v})$ is the mean of stockpile volume. Mst $(\mathrm{v})$ is the expectation value of stockpile volume, when customer still uses his stock product. Mvs (v) is the expectation value of stockpile volume, when customer becomes variety-seeking.

\section{Conclusion}

This research considers variety-seeking as a factor to predict customer active probability. It is different from previous researches such as bivariate-interpurchase time which views switching to other brands as another purchase action. This paper also extends queue question to consider Possion and exponential distribution to portray the dynamic process of customer purchase behavior and provide a new vision of interpurchase time research. This research also use empirical data of service retailers to demonstrate how to use the propose model to calculate the product consumption and product stockpile volume. This result can make application for other industries such as e-commerce.

In the future, other queue models can be considered. The researchers can use different probability distributions to portray different purchase behavior with various characteristics. To explore the variety-seeking behavior of customer, future studies can focus on impact variables that will influence this behavior and use these variables to predict customers' interpurchase time. For example the logistic model can be used to combine the purchasing model and stochastic model.

\section{Acknowledgements}

The author would like to thank the MOT Teach Patrice Research Program, National Science Council of Taiwan (MOST105-2410-H-156-013, 107-2914-I-156-004-A1) and Aletheia University (AU-AR-107-010) for supporting this research.

\section{References}

[1] Pappas, O. I., Kourouthanassis, E. P., Giannakos, N. M. and Chrissikopoulos, V. (2016) Explaining online shopping behavior with fsQCA: The role of cognitive and affective perceptions. Journal of Business Research 69 (2) 794-803.

[2] Grewal, D., Ahlbom, C. P., Beitelspacher, L., Noble, M. S. and Nordfält, J. (2018) In-Store Mobile Phone Use and Customer Shopping Behavior: Evidence from the Field. Journal of Marketing 82 (4) 102-126.

[3] D. Dong, and M. H. Kaiser, "Investigating Coupon Effects on Household Interpurchase Behavior for Cheese," American Agricultural Economics Assosiation Annual Meeting, Long Beach, California, 23-26, July 2006.

[4] Kumar, A. and Kumar, S. (2017) An Empirical Study on the Factors Affecting Online Shopping Behavior of Millennial Consumers. Journal of Internet Commerce 16 (3) 219-230.

[5] Lismont, J., Ram, S., Vanthienen, J., Lemahieu, W. and Baesens, B. (2018) Predicting interpurchase time in a retail environment using customer-product networks: An empirical study and evaluation. Expert Systems with Applications104 (15) 22-32.

[6] Wang, J. H., Malthouse, C. E and Krishnamurthi, L. (2015) On the Go: How Mobile Shopping Affects Customer Purchase Behavior. Journal of Retailing, 91 (2) 217-234.

[7] Igari, R. amd Hoshino, T. (2018) A Bayesian data combination approach for repeated durations under unobserved missing indicators: Application to interpurchase-timing in marketing. Computational Statistics \& Data Analysis 126, 150-166.

[8] Wysocki, A. F. (2005) A Frictionless Marketplace Operating in a World of Extremes. Choices, 20 (4) 263-268. 
[9] Schweidel, A. D., Park, Y. H. and Zainab, J. (2014) A Multiactivity Latent Attrition Model for Customer Base Analysis. Marketing Science 33 (2) 273-286.

[10] Kalyanaraman, R. and Suvitha, V. (2012). A Single Server Compulsory Vacation Queue with Two Type of Services and with Restricted Admissibility. International Journal of Information and Management Sciences 23 (3) 287-304.

[11] Rubio, N, Villaseñor, N. and Yagüe, J. M. (2019) Customer's loyalty and trial intentions within the retailer: the moderating role of variety-seeking tendency. Journal of Consumer Marketing 36 (1) 235-274.

[12] Tian, J., Zhang, Y. and Zhang, C. (2018) Predicting consumer variety-seeking through weather data analytics. Electronic Commerce Research and Applications 28, 194-207.
[13] Baltas, G., Kokkinaki, F. and Loukopoulou, A. (2017) Does variety seeking vary between hedonic and utilitarian products? The role of attribute type. Journal of Consumer Behaviour 16 (1) $1-12$.

[14] Hyewook, G. J. and Aimee, D. (2016) Variety-seeking as an emotional coping strategy for chronically indecisive consumers. Marketing Letters 27 (1) 55-62.

[15] Huang, Z., Liang, Y., Weinberg, B. C. and Gorn, J. G. (2019) The Sleepy Consumer and Variety Seeking. Journal of Marketing Research 56 (2) 1-18.

[16] Niu, B., Chen, L., Liu, Y. and Jin, Y. (2019) Joint price and quality decisions considering Chinese customers' variety seeking behavior. International Journal of Production Economics 213 97-107. 